\title{
Small-Scale Industry, Environmental Regulation, and Poverty: The Case of Brazil
}

\author{
Rajshri Jayaraman and Peter F. Lanjouw
}

\begin{abstract}
Governments and international development agencies have intensified efforts to promote small-scale enterprises as an engine of propoor growth. In Brazil, however, smallscale industries may also be responsible for the bulk of air pollution emissions. Although employees of polluting small-scale industries in Brazil are not disproportionately poor, simulations suggest that stringent environmental regulation resulting in widespread closures of pollution-intensive small-scale industries would result in a nonnegligible increase in poverty among employees of these firms. The results suggest that the enthusiasm for small-scale enterprises needs to be tempered by awareness of the potential environmental costs imposed by this sector.
\end{abstract}

Small-scale enterprises have generated a surge of interest among policymakers and development agencies in recent years. The World Bank and the International Finance Corporation (IFC) have been particularly active in promoting small-scale enterprises, setting up a separate department for them in 2000 and allotting \$1.5 billion toward their development in 2002.

This emphasis is not unwarranted. Small-scale enterprises are the dominant employers in much of the developing world. In Ecuador, for instance, 99 percent of firms have 50 or fewer employees (Lanjouw 1997). In northeast and southeast Brazil, 71 percent of workers are employed in firms with fewer than 20 employees. Despite forming the economic bedrock of most low-income countries, small-scale enterprises often operate in difficult business environments and weak institutional settings, and with little access to physical and human capital (IFC and World Bank 2002). Improving the investment climate faced by smallscale enterprises is therefore increasingly viewed as pivotal to promoting economic growth in low-income countries.

There is also a long-standing belief that "small-scale enterprises in developing countries play a major role in providing income opportunities among the urban

Rajshri Jayaraman is an assistant professor at the University of Munich's Center for Economic Studies; her e-mail address is jayaraman@lmu.de. Peter F. Lanjouw is a lead economist in the Development Research Group at the World Bank; his e-mail address is planjouw@worldbank.org. The authors thank Jenny Lanjouw and David Wheeler for helpful discussions, and they are grateful to the editor and to three anonymous referees for valuable comments and suggestions. They also thank Benoit Dostie and Kiran Pandey for their assistance.

THE WORLD BANK ECONOMIC REVIEW, VOL. 18, NO. 3,

(C) The International Bank for Reconstruction and Development / THE WORLD BANK 2004; all rights reserved. doi:10.1093/wber/lhh048

18:443-464 
poor" (World Bank 1978, p. 9; see also IFC and World Bank 2002; ILO 1991). Poor people typically have a limited endowment of the human capital thought to be necessary for employment in the public sector or in more technologyintensive, large-scale enterprises. Small-scale enterprises more commonly employ unskilled labor.

Improving the investment climate for small-scale enterprises is therefore widely promoted as a means of reaping the double dividend of propoor growth. However, in the rush to embrace small-scale enterprises, there has been little discussion of the potential environmental costs imposed by one subset of such enterprises, small-scale industries. This article examines this aspect of smallscale industries.

The manufacturing sector typically accounts for a small share of total smallscale enterprise employment. In Brazil, for instance, only 9.4 percent of employees in firms with 20 or fewer employees work in the manufacturing sector. Although manufacturing processes tend to use technologies-fuel burning, in particular-that are major contributors to air pollution, different industrial sectors have different emission intensities because of different production technologies. Some industrial processes are simply "dirtier" than others. Paper processing is more emission-intensive than furniture making. Pollution also varies according to firm size, a fact attributable to two types of scale economies. One is public economies of scale: The government may be better able to regulate or monitor pollution from large firms than from less visible small firms. Another is private economies of scale: Larger firms have access to different technologies, associated with different pollution intensities, than smaller firms do.

There is no consensus, however, about whether small-scale industries are more pollution-intensive than large-scale industries. Some argue that smallscale industries may be more environmentally sustainable because of such factors as informal community pressure and regulation (see Schumacher 1989; Blackman and Bannister 1996; Pargal and Wheeler 1996). But there are also contrary views. Beckerman (1995) and Branden (1993) argue that small industries may be more harmful to the environment. As Branden (1993, pp. 4-11) notes, small-scale industries "often pollute more per unit of output than large firms operating in the same sector." This has variously been attributed to their failure to employ more efficient, updated technology; the difficulty of monitoring their compliance with regulations; their inability to safely dispose of the waste they produce; and their limited awareness of the potentially harmful effects of their activities.

Should policymakers be concerned about the environmental costs associated with measures to promote small-scale industries? Are they right in believing that the poor are overrepresented in this sector? Is their concern that regulation aimed at attenuating environmental costs would come at the price of exacerbating poverty?

This article broaches each of these questions in the context of air pollution in the manufacturing sector of Brazil. The findings, based on applying air pollution 
per worker coefficients by industry and firm size from a Mexican emissions study to data from a Brazilian household survey on employment and size of workplace, suggest that small-scale industries contribute a nonnegligible amount to aggregate air pollution in Brazil. Policymakers need to be alert to this environmental consequence of rapid growth in small-scale industry activity. The results also show that the poor are not overrepresented in polluting small-scale industries. Even so, simulations indicate that the most draconian regulation, aimed at eliminating the environmental costs associated with pollution-intensive small-scale industry activity, could exacerbate poverty in Brazil.

\section{Data Sources}

The analysis draws on two data sources: the 1996/97 Living Standards Survey (PPV) for Brazil and the National Information System on Pollution from Fixed Sources (SNIFF) database on air pollution emissions in Mexico. The PPV, fielded in northeast and southeast Brazil by the Brazilian Institute of Geography and Statistics, is a cross-sectional survey of 4,940 households comprising 14,409 individuals and covering 10 major geographical regions. ${ }^{1}$ The PPV is an extremely rich data set. It follows the World Bank's Living Standards Measurement Study format in collecting information on a wide range of household characteristics, including demographic characteristics, education levels, asset ownership, occupation, sector and size of workplace, and incomes and consumption levels. It details 41 sectors of employment, each broken down into subsectors, and describes the size of the firm in which respondents are employed-important for identifying small-scale industries.

Because emissions data by firm sector and size are unavailable for Brazil, emissions data for Mexico are used to simulate emissions for Brazil. Both countries have similar technologies and relative input prices in manufacturing (Dasgupta and others 2002). The SNIFF database, maintained by the National Environment Institute in Mexico’s Environment Ministry, records industrial sector, number of employees, and emissions of conventional air pollutants (such as particulates, sulfur dioxide, nitrogen oxides, and carbon monoxide) for around 6,000 plants. Dasgupta and others (1998) used the SNIFF database to calculate annual airborne suspended particulate emissions in metric tons per employee by firm scale and sector of production. This article applies their calculations to the PPV data to determine the pollution intensity of small- (120 workers), medium- (21-100 workers), and large-scale (101+ workers) firms in 27 industrial sectors. $^{2}$

1. The 10 regions are: Fortaleza, Recife, Salvador, other northeast urban areas, northeast rural areas, Belo Horizonte, Rio de Janeiro, São Paolo, other southeast urban areas, and southeast rural areas.

2. For further details on methodology on calculating pollution coefficients, see Dasgupta and others (1998, 2002). 
Some 64 percent of the economically active population in Brazil are employed in workplaces with 10 or fewer employees, and 71 percent are employed in workplaces with fewer than 20 workers. Less than half the population in the industrial sector (41 percent) is employed in firms of 10 or fewer workers, and only about half (52 percent) work in firms of 20 or fewer. Thus, although small-scale employment dominates in Brazil on the whole, in the industrial sector it is roughly on par with larger-scale employment.

The poverty line for this study was constructed from the PPV data set by Ferreira and others (2003). It is based on the cost of a minimum food basket (yielding 2,288 calories per person per day) plus the cost of some basic nonfood requirements. To correct for the considerable regional price variation in a country as large as Brazil, Ferreira and others also calculate a spatial price index based on the food items covered in the PPV. Both the poverty line (131.97 reals per person per month) and all consumption expenditure measures are expressed in 1996 São Paulo prices.

\section{Do Small-Scale Industries Pollute More Than LARGER INDUSTRIES?}

Before exploring how environmental regulation of small-scale industries would affect poverty, it is worth seeing whether small-scale industries pose enough of a threat to the environment to warrant regulation. After all, policymakers look to small-scale industries to promote propoor growth, and small-scale industries may be more costly to monitor than larger-scale firms. It would be difficult to justify regulation if small-scale industries contribute only marginally to overall pollution loads.

Applying the Mexican SNIFF data on annual particulate emissions in metric tons per employee by firm size calculated by Dasgupta and others (1998) to the Brazilian PPV data shows the contribution of small-scale industries to total air pollution among 27 industrial sectors in Brazil (table 1). Small-scale industries contribute a nonnegligible share of total pollution loads, as measured by particulate matter small enough to be inhaled (at 10 micrograms per cubic meter, $\mathrm{PM}_{10}$ ). In 10 industrial subsectors, small-scale industries account for more than three-quarters of overall sectoral pollution, and in 3 they account for more than half. On aggregate, small-scale industries account for 62 percent of industrial air pollution in Brazil but for only 50 percent of industrial employment.

In general, the evidence points to an environmental protection rationale for regulating small-scale industries. How such regulation would affect the poor is not clear, however.

This study is limited to small-scale industries. Although there may be concerns about environmental stress stemming from agricultural practices and from small-scale services, these are likely to center on common property resource problems (such as overgrazing, deforestation, and water pollution arising from pesticide use) or urban congestion (see World Commission on Environment and 


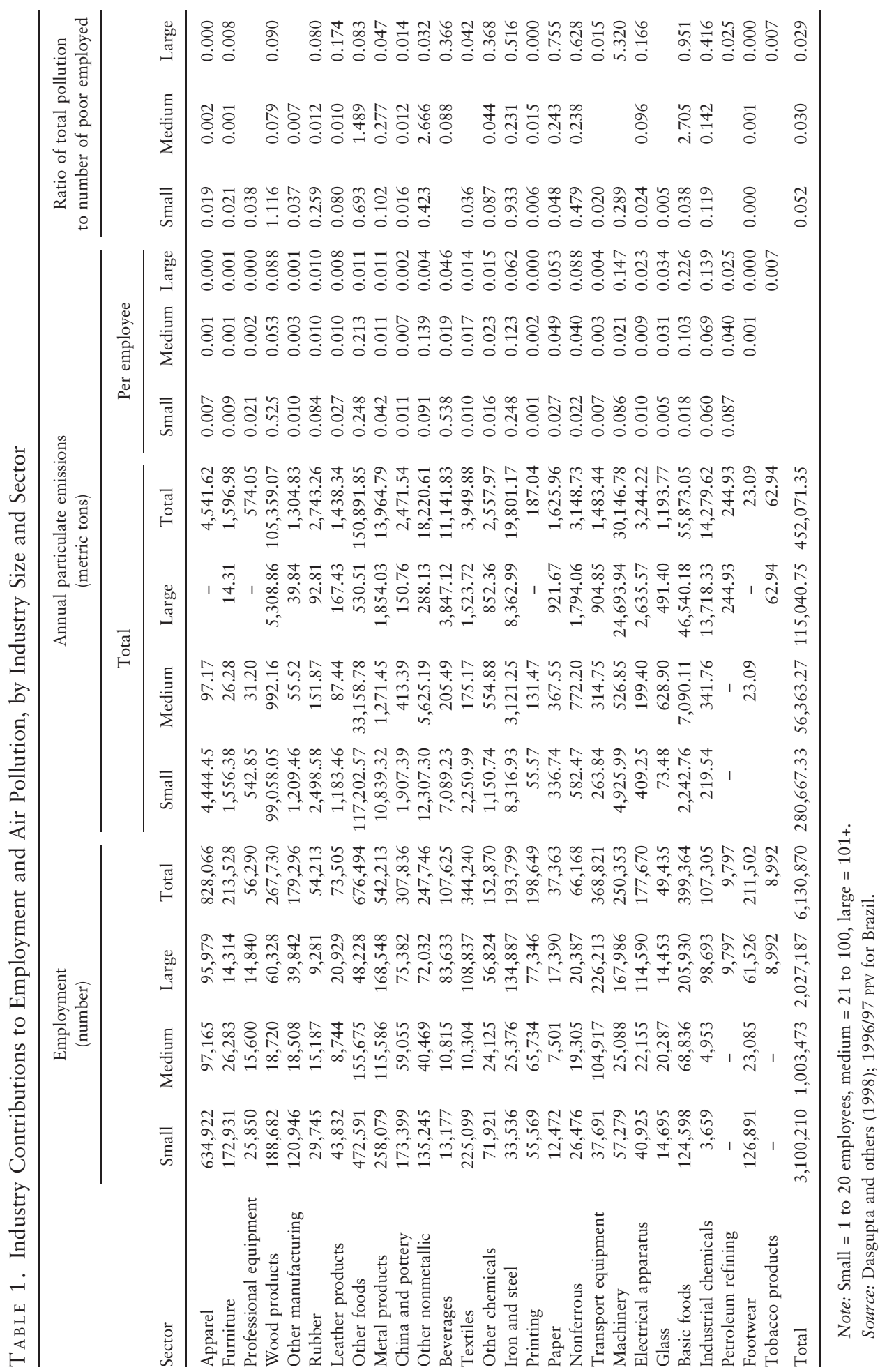


Development 1987). These are important environmental issues meriting further study. However, agriculture and small-scale services are unlikely targets of air pollution regulation, which tends to be directed toward processes that are fuelcombustion intensive.

\section{Small-Scale Industries, Poverty, And Pollution}

The evidence on particulate emissions suggests that governments concerned with environmental pollution have reason to pay attention to small-scale industries. However, governments may be hesitant to intervene if they believe that such regulation would affect the poor disproportionately.

With a few exceptions (textiles, leather products, and beverages), the 13 sectors in which small-scale industries are responsible for the bulk of $\mathrm{PM}_{10}$ pollution also have higher ratios of pollution to the number of poor people employed than the corresponding large-scale firms (see table 1). This suggests that environmental regulation of the worst offenders among small-scale industries may be an effective strategy for reducing emissions while simultaneously minimizing the damage to the poor.

The consequences of regulation for poverty clearly depend on which smallscale industries are targeted. A government wanting to reduce air pollution would presumably concentrate on the small-scale industries with the highest burden of air pollution. But what this means in practice may not be clear. This study considers several scenarios for targeting small-scale industries for regulation.

- Scenario 1: Small-scale industries contributing 50 percent or more of their industrial sector's $\mathrm{PM}_{10}$ emissions (these firms account for 58 percent of total industrial air pollution).

- Scenario 2: Small-scale industries producing higher $\mathrm{PM}_{10}$ emissions per employee than large-scale industries in their industrial sector (these firms account for 60 percent of industrial air pollution in their sectors).

- Scenario 3: Small-scale industries producing higher total $\mathrm{PM}_{10}$ emissions than large-scale industries in their industrial sector (these firms account for 58 percent of industrial air pollution in their sectors).

Government concern with air pollution is not restricted to its environmental costs. A large body of evidence from North America and Western Europe indicates that air pollution from combustion processes is responsible for numerous health problems, ranging from eye irritation to death. Human health damage in urban areas is roughly proportional to the product of $\mathrm{PM}_{10}$ concentration times city population (Pandey and others forthcoming). Polluting smallscale industries in cities where this product is high would be natural candidates for regulation.

A recent World Bank-World Health Organization (WHO) study measured annual concentrations of $\mathrm{PM}_{10}$ for 180 Brazilian cities with populations greater 
than $100,000 .^{3}$ Although the PPV identifies only 10 geographic regions, 6 of these that are identified as cities correspond to the cities in the World Bank's WHO study that are among the worst offenders in the country. ${ }^{4}$ The product of $\mathrm{PM}_{10}$ times city population concentration is the highest in the country in São Paolo and second highest in Rio de Janeiro, followed by Belo Horizonte (4th), Salvador (6th), Fortaleza (7th), and Recife (17th). Thus, two additional scenarios consider what would happen to poverty if regulation were restricted to small-scale industries in these cities:

- Scenario 4: Small-scale industries in six cities with high air pollution as measured by population times $\mathrm{PM}_{10}$ concentration: São Paolo, Rio de Janeiro, Belo Horizonte, Slavador, Fortaleza, and Recife (these firms account for 24 percent of total industrial air pollution).

- Scenario 5: Small-scale industries that produce more than 1,000 metric tons of $\mathrm{PM}_{10}$ emissions in six cities with high air pollution as measured by population times $\mathrm{PM}_{10}$ concentration (these firms account for 19 percent of total industrial air pollution).

Two questions are examined: Does employment of poor people in the smallscale industries targeted under the five scenarios differ systematically from that in other sectors of the economy? What contribution do these firms make to overall poverty among workers? Answering these questions will help verify whether the poor in Brazil are indeed, as often supposed, overrepresented in pollution-intensive industries.

The incidence of poverty among employees of small-scale industries targeted according to pure emissions criteria (scenarios 1-3) is around 37-38 percent (table 2). That poverty differs little across these groups reflects the fact that the sectors targeted under these three scenarios do not vary dramatically. However, small-scale industries targeted under the urban pollution scenarios 4 and 5 have significantly lower poverty rates. Just 25 percent of these workers are poor. Workers in small-scale industries targeted under scenarios 1-3 have significantly higher poverty rates than workers in large-scale industries. Because these three scenarios would target more than 80 percent of workers employed in small-scale industries, this higher poverty rate may explain the common perception that the poor are concentrated in these industrial sectors. However, poverty among workers employed in small-scale industries targeted under the narrower urban pollution scenarios 4 and 5 (targeting fewer than 40 percent of workers employed in small-scale industries) is not significantly different than poverty among employees of large-scale industries. Poverty rates of workers targeted

3. These data were made available by David Wheeler, lead economist in the infrastructure/environment team of the World Bank's Development Research Group.

4. The Brazilian authorities chose not to distribute information regarding the specific location of each household to protect the confidentiality of informants. 


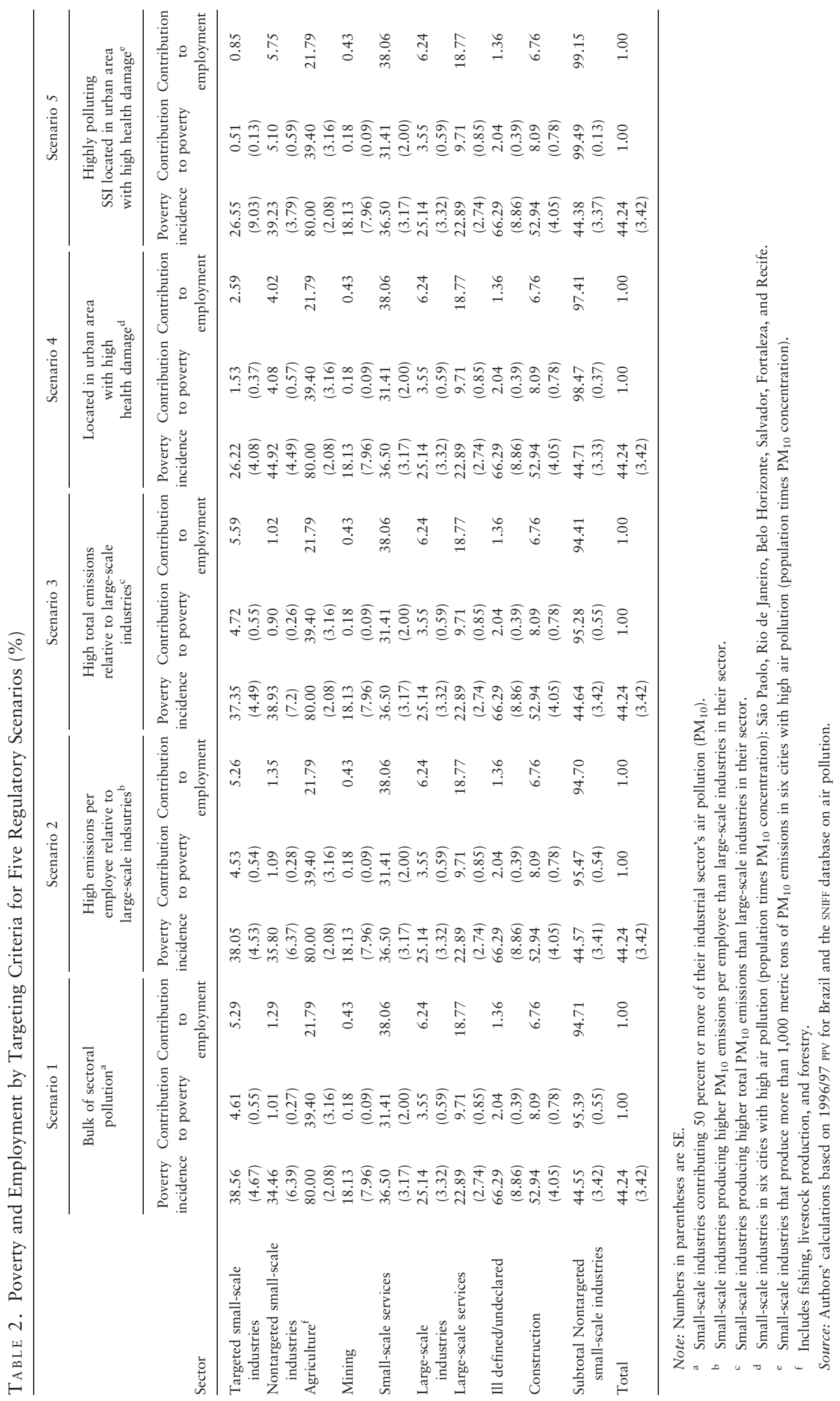


under all five scenarios are markedly lower than that among all workers combined (44 percent), although this difference is not statistically significant.

The data do not confirm the assertion that poor people are disproportionately represented in polluting small-scale industries. Under scenarios 1-3, poor people in targeted small-scale industries account for 4.6-4.7 percent of all poor people while these industries represent 5.3-5.6 percent of the working population. This is in marked contrast to large-scale industries, which constitute 6.24 percent of employment and 3.55 percent of poor people. Poor people in targeted small-scale industries under scenarios 4 and 5 are even more underrepresented: These industries' contribution to poverty is just over half their contribution to employment.

In Brazil poverty is concentrated in small-scale services and agriculture. Poverty rates are not significantly different in small-scale services than they are in small-scale industry as a whole. However, nearly 40 percent of the workforce is employed in this sector, making its contribution to overall poverty extremely high (at 31 percent). In agriculture, the problem is even more severe: 80 percent of workers fall below the poverty line, and they constitute more than 39 percent of the number of poor workers. Moreover, unlike workers in smallscale services, workers in agriculture are overrepresented among the poor because they account for just under 22 percent of employment.

For the original question motivating this study of how poor people would fare if regulation focused on small- rather than large-scale industries, the data suggest that the toll on the poor would be substantially higher if regulation were based on broadly defined emissions criteria. If small-scale industries were more narrowly targeted on the basis of location, the data suggest that there would be little impact on poverty as a result of targeting small- rather than large-scale firms.

\section{Environmental Regulation of Small-Scale Industries ANd Poverty}

The analysis so far suggests that employees of pollution-intensive small-scale industries are not doing too badly relative to the average worker. They are not disproportionately poor, their poverty rates are not significantly different from that of the working population at large, and they do considerably better than employees in some of the other major sectors (especially agriculture). However, these statistics do not by themselves give a firm grasp of how regulation of pollution-intensive small-scale industry would affect poverty. This requires understanding how well employees in this sector are equipped to deal with employment shakeouts ensuing from regulation.

\section{Are Employees of Pollution-Intensive Small-Scale Industries Vulnerable to Poverty?}

Because vulnerability to poverty extends beyond workers to their families, the analysis needs to include the working-age population at large. Overall, the 
data indicate that most poor people are black or mulatto, have little education, and live in urban areas, although households in rural areas are poorer on average.

Do individuals employed in pollution-intensive small-scale industry share these characteristics? Of the 12,892 individuals in the sample, 455 are targeted under scenario 1, 455 under scenario 2, 480 under scenario 3, 365 under scenario 4, and 102 under scenario 5. The results for the probability that an individual ages 15-80 is employed in the sectors targeted under each of the five scenarios, controlling for a variety of individual and household characteristics, are quite consistent (table 3 ). The results show an inverted U-shaped relationship between the probability of working in a polluting small-scale industry and the dependency ratio (ratio of nonworkers in a household to total number of household members). A Kolmogorov-Smirnov equality of distributions test reveals, however, that the families of individuals employed in the targeted small-scale industries do not differ significantly in size from those of employees in other sectors.

Mulattos appear less likely to work in polluting small-scale industries in the six major cities, but otherwise race appears to have no connection with the probability of working in these small-scale industries. Age generally matters, with the probability of working in polluting small-scale industries rising up to ages 35-40 and declining thereafter. With the exception of scenario 1, women are significantly less likely than men to work in these small-scale industries. Educational attainment is also important: Individuals with some primary and secondary schooling are significantly more likely to work in the polluting smallscale sector than those with no education.

Because targeting in scenarios 4 and 5 is based on geographic criteria, regional dummy variables are not included in these two models. However, regional dummy variables play an important role in indicating employment in industries targeted solely by emissions criteria. In particular, all other things equal, individuals residing in Fortaleza have a higher probability of working in polluting small-scale industries than do residents of São Paolo, whereas those in Recife, Salvador, and Rio de Janeiro and those in rural areas have a lower probability. Finally, the larger the proportion of municipal residents working in pollution-intensive small-scale industry, the more likely it is that any given individual in the municipality will be employed in a pollution-intensive smallscale industry. ${ }^{5}$ The role of this variable will become apparent shortly.

Overall, the profile of individuals employed in small-scale industries that are potential targets of regulation does not appear to closely resemble the profile of poor people. As mentioned, poverty tends to be associated with having low levels of education, residing in rural and small urban areas, and being black or mulatto. The probits for working in pollution-intensive small-scale industry

5. Endogeneity is avoided here by omitting the individual in question when calculating this ratio. 


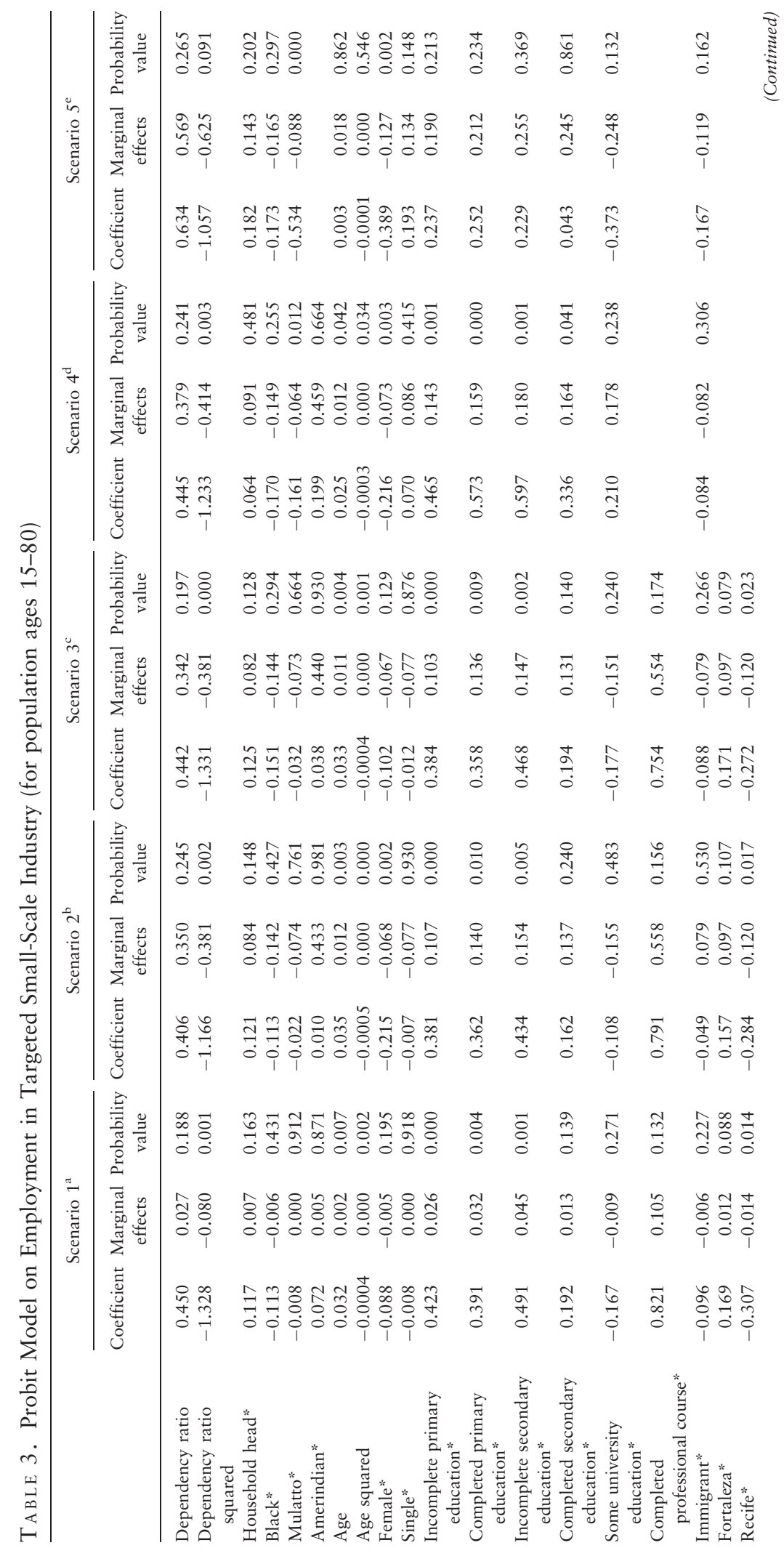




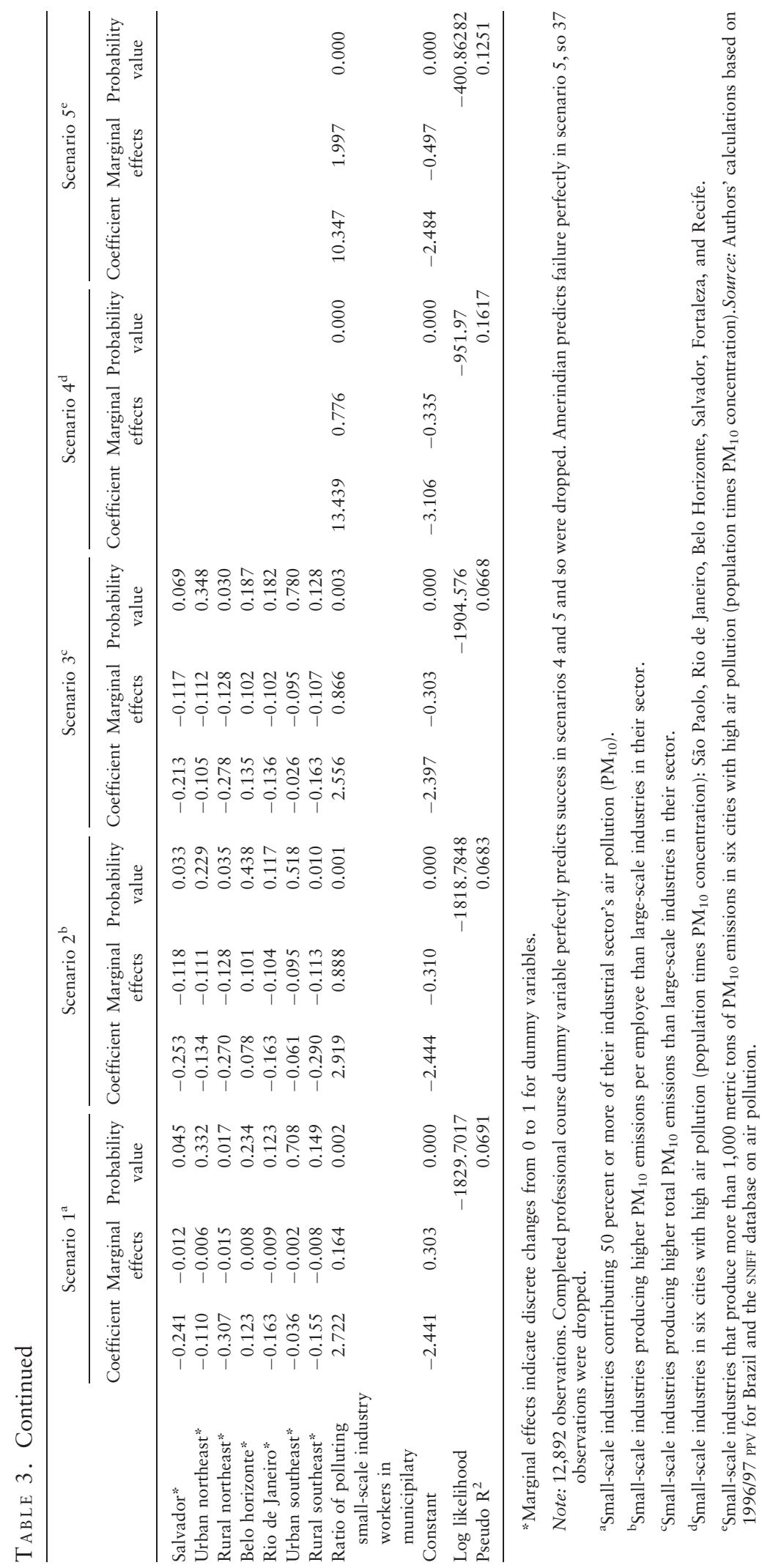


turn out insignificant coefficients for the dummy variable for being black, and mulattos are less likely to work in these industries under the geographic targeting scenario. Models 1-3 also produce insignificant coefficients for the two small urban area dummy variables. The probit regressions further indicate that people with some schooling are more likely to work in polluting smallscale industries than people with no schooling (although the best-educated people in the population are not significantly more likely to be found in pollution-intensive small-scale industries).

\section{A Thought Experiment: Five Scenarios for Regulating Small-Scale Industries}

How would poverty change following environmental regulation of pollutionintensive small-scale industry? Ideally, the answer to this question would require panel data and observation of what happened to employment and poverty in a country that introduced pollution regulation. This option is not available because the data are cross-sectional and regulation is hypothetical. Instead, the question is approached by asking what consumption level a person employed in a pollution-intensive small-scale enterprise might hope to attain outside that sector, given the person's personal attributes and endowments.

Two assumptions are made. First, regulation consists of closing down the polluting small-scale enterprises under each of the five scenarios, so that all employees are out of work. This assumption serves a dual purpose. One, it skirts the issue of differential impacts of environmental regulation depending on the choice of instrument. If environmental regulation is so draconian as to cause a firm to fire all its employees, then it does not really matter whether regulation took the form of market- or incentive-based interventions (including taxes or markets in pollution rights) or command and control methods (technology or performance standards, for instance). Two, in the absence of any firm-level data (on production process or costs, for instance) this assumption seems preferable to making arbitrary assumptions about differential impacts of regulation on employment or wages depending on firm sector or size (the only pertinent firmlevel data available for this study).

The second assumption is that returns to education, unemployment rates, and so on are unaltered in the remaining sectors - a partial equilibrium analysis. In effect, the consumption of individuals who are not subject to regulation is assumed to be unaffected by the regulation, and the workers who become redundant as a consequence of the regulation are assumed to enjoy consumption levels analogous to those of workers in untargeted firms with similar characteristics. Although the relatively small contribution of the pollution-intensive small-scale sectors to total employment makes this assumption less a concern than it would otherwise be, it is nonetheless far from ideal. The alternative would be to create a general equilibrium framework. However, given the degree of structure that would have to be assumed in such a model, it is not clear how much more realistic it would be. Furthermore, these two assumptions 
counterbalance each other to some extent in that the first would tend to overestimate the impact of regulation, whereas the second would underestimate it. ${ }^{6}$

Three simulations are conducted for each of the five regulation scenarios, estimating consumption expenditures if redundant workers join the pool of informal sector workers, if they join the pool of informal sector workers or the unemployed, and if they join the general pool of workers ages $15-80 .^{7}$

The first two simulations attempt to capture the idea that finding another job will be neither costless nor instantaneous. In Brazil, where labor unions are powerful at the firm level (Amadeo and Camargo 1993 estimate a 30 percent union density) and labor markets are segregated by sector (Carneiro 1998), it seems particularly unrealistic to assume that individuals who lose their jobs in the aftermath of regulation could readily find employment in the formal sector. Although this paints a somewhat pessimistic picture (larger, formal sector firms might be expected to replace the output of regulated small-scale firms) this pessimism is countered by the optimistic assumption that returns to labor in the informal sector are unchanged despite the positive shock to labor supply in this sector following job losses by small-scale industry employees (which might otherwise be expected to dampen wages in this sector.)

A more neutral picture is offered by the third simulation, which bases the estimated consumption of redundant workers on average consumption of the remainder of the working-age population (unemployed and in formal or informal sector employment). The resulting estimate of poverty is not obviously biased in any direction, particularly given the small number of redundant workers.

\section{The Exercise and Econometric Issues}

The object of the thought experiment is to understand how poverty among those currently employed in pollution-intensive small-scale industry would evolve as a result of redundancy following the introduction of draconian regulation. Doing that requires an understanding of how employees of polluting small-scale industries would fare if they were to join the pool of informal sector employees and the unemployed. One way of doing this would be to estimate an ordinary least squares (OLS) regression of expenditure on the personal characteristics of the pool of informal sector employees and the unemployed and then use these estimates to predict the expenditures of employees of polluting small-scale industries following regulation.

6. Research from the European Union suggests that the overall employment effect following environmental regulation is most often positive, although a few studies note a neutral or slightly negative employment effect (ILO 1990, p. 42). Therefore, the implicit assumption that the net employment effect is unchanged seems reasonable.

7. Participation in the formal sector is defined as having a license for the self-employed and as holding a work card (carteira assinada) for employees. Where this information was unavailable, it is defined as contributing to social welfare (instituto de previdência). 
However, such an exercise is likely to yield biased estimates. In particular, the unobserved characteristics of employees in the informal sector or of the unemployed may differ systematically from those of employees of polluting smallscale industries. For instance, informal sector employees may lack the connections necessary to acquire more secure employment, and the unemployed might have high reservation wages. Without data on such personal characteristics, therefore, the conditional expectation of the error term in an ols regression is likely to be nonzero, yielding inconsistent estimators. ${ }^{8}$

To conduct the thought experiment, estimates from the following equation are applied to employees of polluting small-scale industries:

$$
E\left(y_{i 2} \mid x_{i}, y_{i 1}=1\right)=x_{i 2}^{\prime} \beta_{2}+E\left(u_{i 2} \mid u_{i 1}>-x_{i 1}^{\prime} \beta_{1}\right)
$$

where $x_{i 1}$ is a vector of individual $i$ 's personal characteristics, $y_{i 2}$ denotes the log of $i$ 's per capita expenditure, $y_{i 1}=x_{i 1}^{\prime} \beta_{1}+u_{i 1}=1$ if $i$ is either unemployed or employed in the informal sector (but not in polluting small-scale industries), and $u_{i}$ is the error term. Assuming normality of the error terms and integrating equation 1 reduces to:

$$
E\left(y_{i 2} \mid x_{i}, y_{i 1}=1\right)=x_{i 2}^{\prime} \beta_{2}+\tau \lambda\left(x_{i 1}^{\prime}\left[\beta_{1} / \sigma_{1}\right]\right)
$$

The last term in equation 2 is essentially a bias correction term, where $\lambda(z)=\phi(z) / \Phi(z)$ is the inverse Mill's ratio.

The estimation proceeds in three steps. First, Heckman's (1976) two-step method is used in estimating equation 2. Step 1 estimates $\alpha_{1}=\beta_{1} / \sigma_{1}$ with a probit model. Step 2 regresses $y_{i 2}$ on $x_{i}$ and $\lambda\left(x_{i 1}^{\prime} \hat{\alpha}_{1}\right)$ by least squares for the reference population (the pool of individuals that redundant employees of smallscale polluting industries are expected to join).

Second, the estimates for $\beta_{2}$ are used to predict consumption of the smallscale enterprise employees, were they to join one of the three pools: employees of the informal sector, informal sector employees and the unemployed, and the general working population ages 15-80. Next, residuals (a different one for each household) are drawn from the assumed normal distribution and added to the predicted consumption measures. This exercise is repeated 100 times, and the summary poverty measures are calculated after each draw. The FosterGreer-Thorbecke (FGT) class of poverty measures is used, with parameter values 0,1 , and 2 . A mean over the 100 respective poverty measures provides an estimated poverty rate following the switching out of the employees of the pollution-intensive small-scale enterprises into the hypothetical pools. This yields a measure of predicted poverty in the reference group following regulation, which can then be compared with current (observed) poverty levels.

8. The remainder of the section draws largely from Jakubson (1998). 
There is one further econometric issue to consider before estimation. Heckman's two-step method yields consistent estimates for $\alpha_{1}, \tau, \beta_{2}$, and $\sigma_{22}$. Although in theory this serves to identify the remaining elements of the parameter variance matrix $\left(\sigma_{2}, \sigma_{12}\right.$, and $\left.\sigma_{1}\right)$ even when $x_{i 1}=x_{12}$, such identification relies on the functional form (essentially the curvature of the $\lambda$ function) for identification. This is not an attractive means of identification because there is no theoretical basis for preferring one functional form over another. It is preferable to use an exclusion variable as a means of identification-a variable that affects an individual's employment status but not the expenditure outcome.

The identifying variable used here is the ratio of (other) individuals working in pollution-intensive small-scale industry to the total number of individuals residing in a particular municipality. This ratio is expected to have a negative effect on the chances of observing a worker in the non-pollution-intensive small-scale sector, but there is no reason to expect that it would affect the expenditure levels of workers. The value of this ratio will differ for every household because it is calculated excluding the respective household from both the numerator and denominator of the ratio.

\section{Results}

Rather than detail the results from Heckman's two-step method, which largely mirror those presented in table 3, two key points are worth highlighting. First, the probit coefficient on the ratio of individuals working in pollution-intensive small-scale industries within a given municipality is negative and highly significant, suggesting that this exclusion has bite.

Second, the presence of a sample selection problem is confirmed in two ways. First, the coefficient on $\lambda$ is significant, so the null hypothesis that there is no sample selection problem is rejected. Second, there are a few large differences in coefficients when the expenditure equation is estimated using standard oLs, particularly for the primary education and geographic location coefficients. This suggests that unobservables play an important role in explaining the sector of employment (and unemployment) and thereby incomes.

For these reasons coefficients and residuals from the Heckman two-step method are used to predict expenditures for employees of polluting small-scale industries under all five scenarios. Results of the final stage of the simulationcomparison of poverty before and after the regulation-are reported in table 4, which provides poverty rate calculations of the incidence $(F G T)$, poverty gap (FGT1), and squared poverty gap (FGT2) for individuals ages 15-80 currently employed in pollution-intensive small-scale industries. The base case refers to observed poverty. The informal case refers to predicted poverty if employees of pollution-intensive small-scale industries lose their jobs and find employment in the informal sector subsequent to regulation. The informal and unemployed case adds the currently unemployed to informal sector employees to see what would happen to poverty were redundant workers to join this larger pool. Finally, the general population case looks at what would happen to poverty 
Table 4. Poverty among Current Employees of Targeted Small-Scale Industries before and after Regulation

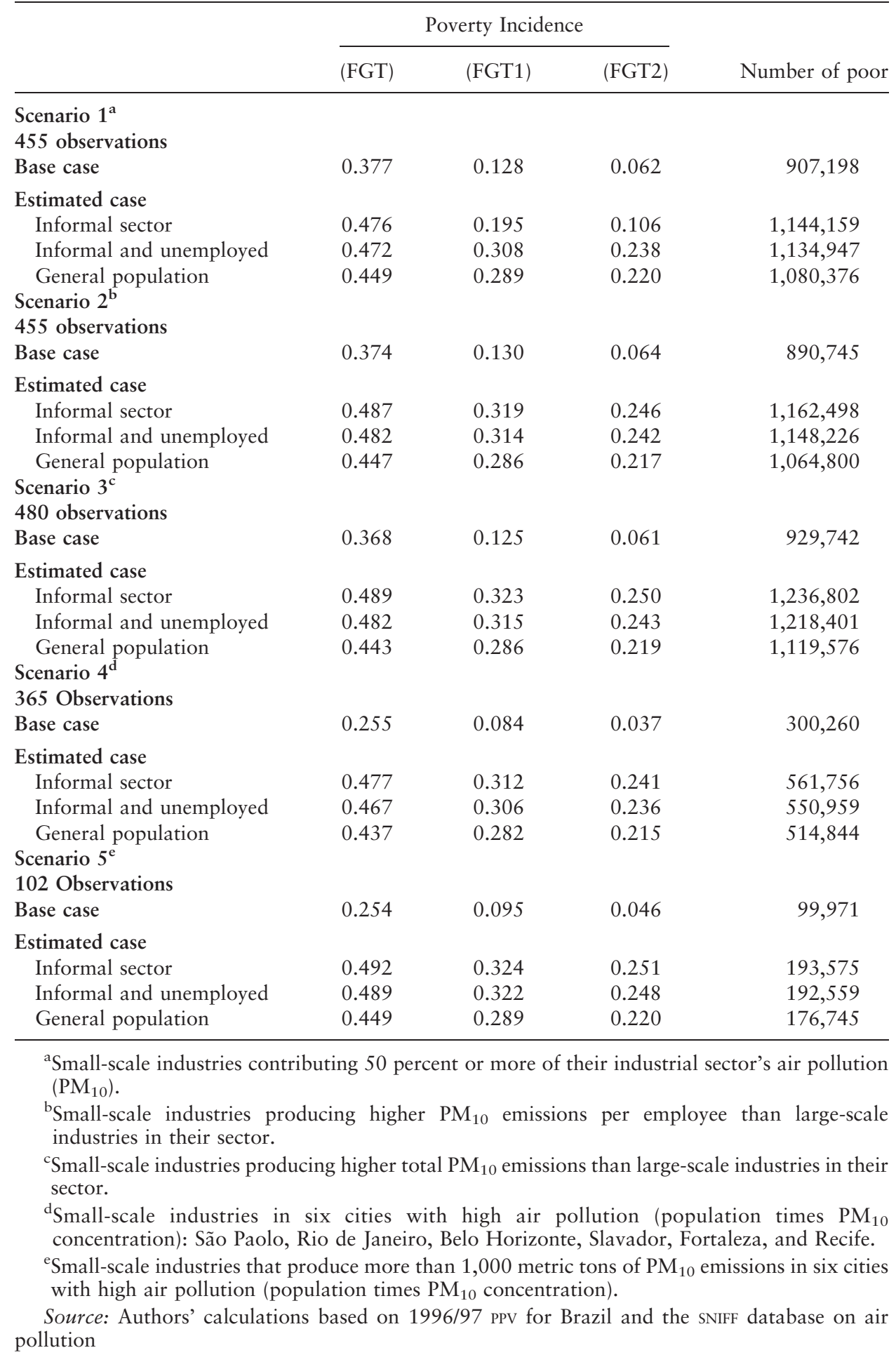


were redundant workers in targeted small-scale industries to join the general working population ages $15-80$.

Scenarios 1-3 describe base case and estimated poverty rates if small-scale industries are targeted on the basis of their contribution to pollution. Although different groups of individuals are targeted under each scenario, neither the base case nor the estimated poverty rates are significantly different across groups. Base case poverty lies between 37.7 and 36.8 percent among these three target groups. Were the targeted small-scale industries to be shut down and redundant workers to join the pool of informal sector workers, poverty among the targeted groups would increase by between 26 percent and 33 percent, raising poverty rates to between 47.6 percent and 48.9 percent-corresponding to between 230,000 and 290,000 more people in poverty. If redundant workers joined the group of unemployed and informal sector employees, poverty would increase by slightly less (between 25 percent and 31 percent). Although this may seem counterintuitive, in Brazil most of the unemployed are former formal sector workers, who alone are eligible for unemployment benefits, which are often a percentage of previous earnings. As a result, the unemployed may well be better off than many who are employed but working in the informal sector. Finally, the increase in poverty is significantly lower under the more optimistic scenario in which redundant workers join the general working age population. Even then, however, poverty rises by between 19 percent and 20 percent, or an additional 173,000-180,000 people.

At just over 25 percent, base case poverty is much lower in scenarios 4 and 5 , which target small-scale industries by geographic location. Increases in poverty are much more dramatic, however. When regulation shuts down all small-scale industries in São Paolo, Rio de Janeiro, Belo Horizonte, Salvador, Fortaleza, and Recife, poverty increases by 87 percent when redundant workers join the informal sector, by 83 percent when they join the pool of informal sector workers and the unemployed, and by 72 percent when they join the general working age population. The increase in poverty is 6,9 , and 5 percentage points higher in each case when the target group in these cities is restricted to smallscale industries producing more than 1,000 metric tons of particulate emissions. Narrowing the target population to the most polluting small-scale industries results in at least 300,000 fewer individuals in poverty following regulation. Indeed, basing targeting on geographic criteria rather than broader aggregate pollution criteria reduces both the number of individuals targeted and the estimated number of poor people.

In addition to a rise in the incidence of poverty, there is a marked deepening of poverty, irrespective of the assumed pool into which redundant employees fall, especially under scenarios 4 and 5 . The increase in the poverty gap (FGT1) and squared poverty gap (FGT2) vary dramatically depending on the target group and the assumptions regarding which pool redundant workers join. The increase in the poverty gap ranges from 52 percent (when redundant workers from small-scale industries that contribute to at least 50 percent of overall 
sectoral pollution join the informal sector) to 270 percent (when redundant workers from small-scale industries in the six major cities join the informal sector). The corresponding increases for the poverty gap squared are 69 percent and 543 percent.

\section{Conclusion and Policy Implications}

The analysis in this article indicates that the contribution of small-scale industries to pollution in Brazil is far from marginal. Such firms can be viewed as disproportionately large polluters in the sense that they contribute more to overall industrial air pollution than they do to industrial employment. Indeed, in the data used here, small-scale industries are responsible for the bulk of industrial pollution in Brazil. There is thus a clear environmental rationale for looking closely at pollution control of small-scale industries. Such regulation may have an additional welfare benefit to the extent that firms brought under environmental regulation also impose pollution-related health costs on their employees and on nearby populations. However, the environmental and health benefits from regulation would have to be weighed against the potential for an accompanying increase in the incidence of poverty.

The simulations suggest that shutting down the small-scale industries that produce the most air pollution (as described in scenarios 1-3) would reduce particulate emissions by more than 260,000 metric tons annually, amounting to a 58 percent reduction in aggregate air pollution. ${ }^{9}$ The target group in such a scenario would, however, cover the bulk of small-scale employees, and closure of these firms would result in an estimated 200,000 additional people in poverty-a more than 25 percent increase in the poverty rate for the current employees of the targeted small-scale industries.

If regulation is targeted instead to small-scale industries in major cities, the simulated increase in the number of people in poverty following closure of such firms is smaller. However, there is a dramatic increase in the poverty rate and a smaller drop in particulate emissions of only 100,000 metric tons. Narrowing the target group further to the most polluting small-scale industries in major cities also increases the poverty rate substantially, although the number of newly poor people is relatively low: roughly one-half to one-third of that under the other four scenarios. This comes at a cost of an even lower reduction in particulate emissions of roughly 90,000 metric tons.

The simulations thus suggest that in terms of both environmental benefits and distributional costs, draconian regulation of small-scale industries could be

9. This is an unreasonably optimistic outcome. In reality, if pollution-intensive small-scale industries were shut down as a result of draconian regulation, large-scale firms operating in the same sectors would expand their production to accommodate aggregate demand. This expansion of production would be associated with an increase of pollution (albeit possibly less than the reduction accompanying the departure of the pollution-intensive small-scale industries). 
expected to have quantitatively important consequences. The estimated poverty impacts warrant reflection. The results show that on balance employees of polluting small-scale industries are substantially better equipped than most others to cope with the potential repercussions of regulation, such as finding a new job should they lose their current one. Although they are not the best educated, they enjoy relatively high levels of education, they are more likely to live in areas with greater employment opportunities, and they are more likely to belong to more advantaged racial groups. If this group fares so badly when regulation pushes them out of employment, more disadvantaged groups—such as agricultural or construction workers-could suffer even more if they were to be subjected to similar environmental regulation. Any regulation aimed at such groups-such as measures to contain deforestation or to limit urban growthshould be approached with sensitivity to the potential consequences for the poor.

In thinking about the potential environmental benefits from regulation of small-scale industries, it is important to emphasize that numerous reasons remain to focus as well on large-scale industries. In the face of international pressure and growing private sector understanding that environmental degradation is in many instances reaching unsustainable proportions, governments face a choice of which industries to regulate rather than whether to regulate. Although small-scale industries may well be responsible for more air pollution than large-scale industries, promoting small-scale industries while regulating large-scale industries may be a preferable means of reaping propoor, proenvironmental growth. The incidence of poverty tends to be substantially lower in large-scale industries than in small-scale industries and among workers at large, and the poor are significantly underrepresented in this group. The rationale for regulating large- rather than small-scale industries is bolstered when the higher costs of monitoring small-scale industries is also considered. Finally, large firms are probably also less likely to impose health costs on the poorest members of society for reasons of technology and location.

The picture painted in this study looks stark. But the scenarios described are extremely tentative and possibly unrealistically grim. First, the pollution coefficients for Mexico may not be appropriate for Brazil. Second, it is most unlikely that regulation would be so draconian as to force polluting small-scale industries to shut down altogether. Indeed, empirical evidence on the net employment effect of the environmental regulation seen in practice is mixed (ILO 1990). Third, the fact that employees of polluting small-scale industries are reasonably well endowed in human capital means that they are likely to be reasonably well equipped to find jobs, possibly even in the formal sector. Assuming full-scale redundancy and minimal opportunities may therefore be regarded as a worstcase scenario.

However, it is also clear from the greater responsiveness to the simulations of the distribution-sensitive poverty measures that within the pollution-intensive small-scale sector there are many workers who are well below the poverty line. 
In the event of less draconian regulation, these workers would likely be the first to be made redundant (because of less bargaining power or fewer and weaker networks within the firms). If so, these workers would also be particularly poorly placed for finding formal sector jobs.

The main message from this study is a cautionary one. Attention to smallscale enterprises as a means of promoting propoor growth must be traded off against the potentially non-negligible environmental costs imposed by smallscale industries. At the same time, policymakers should be wary of environmental regulation of small-scale industries because of the potential consequences for poverty. The tradeoffs might be avoided if efforts to improve the business climate for small-scale enterprises focused on the small-scale services sector. This sector, also important to the poor, does not impose the same types of environmental or health costs that small-scale industries do.

There has been virtually no critical debate over the current popularity of promoting small-scale enterprises as a means of stimulating propoor growth. There are clearly many more questions that remain unanswered. What is the real contribution to overall air pollution by small-scale industries in Brazil? What about other types of pollution? What would happen if regulation were less draconian? What kind of regulatory instruments are available? Should efforts to promote the small-scale sector be focused on services rather than industry? What other tradeoffs are there besides an environmental one? This article is one attempt to begin the discussion and to encourage research.

\section{REFERENCES}

Amadeo, E. J., and J. M. Camargo. 1993. "Labour Legislation and Institutional Aspects of the Brazilian Labour Code." Labour 7(1):157-80.

Beckerman, W. 1995. Small Is Stupid: Blowing the Whistle on the Green. London: Duckworth.

Blackman, A., and G. Bannister. 1996. "Community Pressure and Clean Technologies in the Informal Sector: An Econometric Analysis of the Adoption of Propane by Traditional Brickmakers in Cd. Juarez, Mexico.” Resources for the Future Discussion Paper 97-16. Washington, D.C.

Branden, Carter. 1993. Towards an Environmental Strategy for Asia. Discussion Paper 11831-ASIA. Washington, D.C.: World Bank.

Broad, Robin. 1994. “The Poor and the Environment: Friends or Foes?” World Development 22(6): 811-22.

Carneiro, Francisco G. 1998. "Productivity Effects in Brazilian Wage Determination.” World Development 26(1):139-53.

Dasgupta, Susmita, Robert E. B. Lucas, and David Wheeler. 1998. "Small Manufacturing Plants, Pollution and Poverty: New Evidence from Brazil and Mexico.” Policy Research Working Paper 2029. World Bank, Development Research Group, Infrastructure and Environment, Washington, D.C.

—. 2002. "Plant Size, Industrial Air Pollution and Incomes: Evidence from Mexico and Brazil." Environment and Development Economics 7(2):365-81.

De Mello Lemos, Maria Carmen. 1998. "The Politics of Pollution Control in Brazil: State Actors and Social Movements Cleaning up Cubatão.” World Development 26(1):75-87.

Deaton, Angus. 1997. The Analysis of Household Surveys: A Microeconometric Approach to Development Policy. Baltimore, Md.: Johns Hopkins University Press. 
Ferreira, F., P. Lanjouw, and M. Neri. 2003. "A New Poverty Profile for Brazil Using PPv, PNAD and Census Data.” Revista Brasileira de Economia 57(1):59-92.

Heckman, James. 1974. "Shadow Prices, Market Wages and Labour Supply.” Econometrica 42:475-92.

- 1976. "The Common Structure of Statistical Models of Truncation, Sample Selection, and Limited Dependent Variables and a Simple Estimator of Such Models.” Annals of Economic and Social Measurement 5(4):475-92.

—. 1979. "Sample Bias as a Specification Error." Econometrica 47(1):153-62.

IFC (International Finance Corporation) and World Bank. 2002. 2002 Review of Small Business Activities. Washington, D.C.

ILO (International Labour Organization). 1990. Environment and the World of Work: Report of the Director-General. Geneva: International Labour Office.

1991. The Dilemma of the Informal Sector - Report of the Director General (Part 1). Geneva: International Labour Office.

Jakubson, George. 1998. "Notes on Estimators.” Cornell University, Ithaca, N.Y.

Lanjouw, Peter. 1997. "Small-Scale Industry, Poverty and the Environment: A Case Study of Ecuador." Policy Research Working Paper 18. World Bank, Policy Research Department, Washington, D.C.

Lanjouw, Peter, and Martin Ravallion. 1995. "Poverty and Household Size." Economic Journal 105(433):1415-34.

Pandey, K. D., K. Bolt, U. Deichmann, K. Hamilton, B. Ostro, and D. Wheeler. Forthcoming. The Human Cost of Air Pollution: New Estimates for Developing Countries. Washington DC: World Bank.

Pargal, S., and D. Wheeler. 1996. "Informal Regulation of Industrial Pollution in Developing Countries: Evidence from Indonesia.” Journal of Political Economy 104(6):1314-28.

Schumacher, E. F. 1989. Small is Beautiful: Economics As If People Mattered. New York: Harper Collins.

World Bank. 1978. Employment and Development of Small Enterprises. Washington, D.C.

1992. World Development Report 1992: Development and the Environment. New York: Oxford University Press.

World Commission on Environment and Development. 1987. Our Common Future. ["The Brundtland Report"]. New York: Oxford University Press. 